\title{
RANKING OF TOXIC COMPOUND CONCENTRATIONS AS DIAGNOSTIC PARAMEETRS OF MARINE INTERNAL COMBUSTION ENGINE
}

\author{
Ryszard Zadrąg \\ Tomasz Kniaziewicz \\ Polish Naval Academy, Gdynia, Poland
}

\begin{abstract}
Changing selected engine structure parameters, especially fuel system parameters, affects the emission of harmful compounds in the exhaust gas. Changes in harmful compound emission are frequently ambiguous, as they highly depend on parameters controlling the combustion process. An additional problem is that simple interactions are frequently accompanied with mutual influence of these parameters. Therefore, we can say about different sensitivity of diagnostic parameters to the same excitations coming from the engine structure but executed at different loading states. When the set of diagnostic parameters is numerous and the values of these parameters are similar, there is a real problem with their correct classification, frequently based on subjective assessment by the analyst. In the article, the authors propose a methodology to classify the recorded diagnostic parameters. In earlier works by the authors [4,6,7], the information capacity index method (the Hellwig method) was proposed as the measure of diagnostic parameter sensitivity. Based on this method, a rankling of diagnostic parameters can be created which divides the set of diagnostic variables into stimulators and destimulators. Novel authors' approach to the presented problem consists in including nominants, i.e. variables with the most favourable value for the analysed aspect of the research, in the set of diagnostic variables. This normalisation of the set is believed to be helpful for making a diagnostic decision free from analyst's arbitrariness. The zero unitarization method can also be helpful in creating diagnostic tests.
\end{abstract}

Keywords: diagnostic model, Diesel engine, exhaust components, ranking of parameters

\section{INTRODUCTION}

Transient states are special states in internal combustion engine operation, as they interfere into thermodynamic equilibrium of the cylinder, reached during steady engine load periods. This affects the course of the combustion process by, first of all, transient changes of the flow of fresh charge delivered to the cylinder, but also by changing the rate of the delivered fuel. Thus, the fuel/air ratio changes temporarily, which results in changes in the excess air number and, consequently, increased emission of combustion products created at local oxygen deficit. Further consequence of the appearance of the increased volume of $\mathrm{CO}$ and unburned hydrocarbons $\mathrm{HC}$ is the decrease of the combustion temperature, which decides upon reduction in emission of nitrogen oxides $\mathrm{NO}_{\mathrm{x}}$.

Thus, the decisive factor for the amounts of toxic compounds emitted in transient states is the scale of excitations provoking these states. However, an additional factor which also should be taken into account is technical condition of the engine. This condition, described by engine structure parameters, is subject to permanent changes during engine operation, and it is wear processes which are responsible for this. The increasing engine wear intensifies changes in the creation of toxic compounds during transient states, as those processes, although short-lasting, are so dynamic in their nature that instantaneous concentrations of toxic compounds exceed the steady-state levels by many times. Consequently, we may 
expect that the engine with structure parameters changed due to wear will be more sensitive to the action of transient states and thus determining its technical condition will be easier. However, a problem arises how to identify unambiguously the sensitivity of diagnostic parameters, and not only the parameters alone. This problem gains in importance in cases of large amount of research material and/or high variability of transient state courses. The abovementioned sensitivity of the diagnostic parameter can be defined as information capacity, and its value can be used for selecting parameters which best describe the analysed phenomenon $[4,6,7]$.

A basic parameter which decides upon the correctness of the combustion process in Diesel engines is the fuel injection timing. Even small deviations of this parameter result in significant changes of basic engine operation parameters, including exhaust gas emission indicators. In classical engine constructions, self-acting change of fuel injection timing is highly unlikely to occur. However, in modern constructions, in which the majority of control parameters is controlled electronically, a situation can occur which will lead to damage of the control system, with the resultant change of fuel injection timing.

The present work is continuation of the issues analysed by the authors in $[6,7]$. Here, the authors' attention was focused on defining and analysing the information capacity of the diagnostic parameter, which is, as already mentioned, a set of coefficients and characteristics of exhaust gas component emission.

\section{EXAMINING INFORMATION CAPACITY INDICES OF TOXIC COMPOUND CONCENTRATIONS DURING DYNAMIC PROCESSES}

The object of examination was the fuel supply system (the fuel injection timing) of a single-cylinder test engine 1-SB installed at the Laboratory of Power Plan Operation, Polish Naval Academy [5]. The experimental material was collected based on a trivalent complete test plan. According to the test plan, measurements in individual systems (measuring points) were performed using a programmable controller, which made it possible to reach high repeatability of dynamic processes. The dynamic process duration time was assumed equal to the time between the beginning of parameter change in injection system elements and new stabilisation of output parameters. This time was selected experimentally as approximately equal to $106 \mathrm{sec}$.

To identify the effect of technical condition of the fuel supply system on energy parameters of the engine during dynamic processes, sets of input quantities (asked parameters) and output quantities (observed parameters) were defined.

For the purpose of present work, the set of input quantities $X$ was limited to three elements, which were: $x_{1}$ - engine rotation speed $n[\mathrm{rpm}] ; x_{2}-$ engine torque $T_{t q}[\mathrm{~N} \cdot \mathrm{m}] ; x_{3}-$ fuel injection timing $\alpha_{w w}\left[{ }^{\circ} \mathrm{OWK}\right]$. The analysis was performed in accordance with the adopted complete plan for three rotational speeds equal to: 850,950 and 1100 [rpm]. For each rotational speed, the torque $T_{t q}$ was increased to the load of 10 , $20,30,50$ and $70[\mathrm{Nm}]$, thus generating subsequent transient states. For the rotational speed of $850 \mathrm{rpm}$, the loads of 50 and $70 \mathrm{Nm}$ were abandoned to avoid significant engine overload. The same was done for the rotational speed of $950 \mathrm{rpm}$ and load of $70 \mathrm{Nm}$. The fuel injection timing was changed by $\mathrm{o} \pm 5^{\circ} \mathrm{OWK}$, thus obtaining three values, i.e. nominal timing $\mathrm{N}$, advanced timing $\mathrm{W}$, and delayed timing $\mathrm{P}$. This way 36 repeatable transient states were obtained. The functional model of the examined object is schematically shown in Fig. 1.

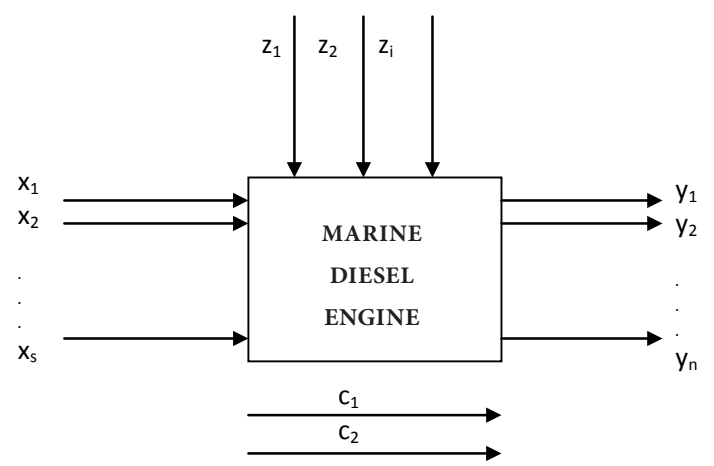

Fig. 1. Quantities characterising the examined object:

$x$ - input quantities, $y$-output quantities, $z$ disturbances, $c$ - constants

A similar procedure was applied to the set of output quantities $Y$ limiting the number of its elements only to basic toxic compounds in the exhaust manifold: $y_{1}$ - carbon oxide concentration in the exhaust manifold $C_{C O}$ [ppm]; $y_{2}$ - hydrocarbon concentration in the exhaust manifold $C_{H C}[\mathrm{ppm}] ; y_{3}-$ nitrogen oxide concentration in the exhaust manifold $C_{N O x}[\mathrm{ppm}], y_{4}$ - exhaust gas temperature $t_{s p}\left[{ }^{\circ} \mathrm{C}\right]$, $y_{5}$ - excess air number $\lambda$.

The detailed analysis of dynamic processes was performed using the data measured during an active experiment and the multi-equation model created based on these data [5]. Both the empirical and model data underwent statistical identification. Equation coefficients of particular output variables were estimated using the least-squares method. The estimation aimed at verifying the significance of parameters and resultant rejection of quantities of minor significance. All this has finally led to significant simplification of the models. The Pearson correlation coefficient was assumed the measure of strength and direction of correlation between examined variables $(Y, X)$.

The correlation coefficients between the variable $Y$ and variables $X_{k}$ compose the correlation coefficient vector $\mathbf{R}_{\mathbf{0}}$, while the correlation coefficients between individual explanatory variables $\left(X_{k}, Y_{s}\right)$ compose the correlation coefficient matrix $\mathbf{R}$ having the form (1):

$$
\boldsymbol{R}_{\mathbf{0}}=\left[\begin{array}{c}
r_{y x_{1}} \\
r_{y x_{2}} \\
\vdots \\
r_{y x_{K}}
\end{array}\right]_{K \times 1}, \boldsymbol{R}=\left[\begin{array}{cccc}
r_{x_{1} x_{1}} & r_{x_{1} x_{2}} & \ldots & r_{x_{1} x_{K}} \\
r_{x_{2} x_{1}} & r_{x_{1} x_{2}} & \ldots & r_{x_{2} x_{K}} \\
\vdots & \vdots & \ddots & \vdots \\
r_{x_{K} x_{1}} & r_{x_{K} x_{2}} & \ldots & r_{x_{K} x_{K}}
\end{array}\right]_{K \times K}
$$


The presented analysis of the obtained results reveals a great advantage of multi-equation models, which is a possibility of multi-criteria analysis of output quantities when they are mutually corelated. However, despite their clear advantages, multi-equation models do not provide directly the information on the quality of changes, i.e. in the analysed case: concentration changes of individual toxic compounds resulting from the change of fuel injection timing. Only combining together transient courses which were experimentally recorded or obtained from the model analysis brings some picture of the phenomenon. Individual relations, along with examination of model fitting to the values obtained from the experiment performed on the engine, are described in detail in $[3,4,5]$.

As already mentioned, the concentrations of individual toxic compounds in transient states reveal some regularity and repeatability. However, this does not make the analysis easier, due to high similarity of all transient states, regardless of the values of applied excitations. Therefore, a method was to be found which would be able to describe as precisely and objectively as possible the nature of changes of individual concentrations of toxic compounds. This method is believed to consist in analysing correlations of individual transient states. In this method, the correlation of the examined transient state with that assumed as the reference pattern for the analysed phenomenon is assessed. The correlation function analysis makes it possible to determine the degree and nature of the correlation. After analysing function components, we may conclude about the abovementioned nature of the transient state, i.e. about the presence and intensity of its individual phases.

A method to select explanatory variables for the model (input quantities for the test plan) based on correlation coefficient values is the information capacity index method (the Hellwig method) [6,7]. This method consists in selecting a combination of variables for which the information capacity is the greatest. The information carriers in that case are all possible explanatory variables. The arrangement of the test plan imposes a number of possible combinations. In the analysed case, for the three assumed input quantities, $K=3$ ( $x_{1}$ - engine rotation speed $n[\mathrm{rpm}] ; x_{2}$ - engine torque $T_{t q}$ $[\mathrm{N} \cdot \mathrm{m}] ; x_{3}-$ fuel injection timing $\left.\alpha_{w w}\left[{ }^{\circ} \mathrm{OWK}\right]\right)$, the number of possible combinations is:

$$
L(K)=2^{K}-1
$$

This way, for each dependent (output) value the following combinations exist:

- single-element combinations: $\mathrm{C}_{1}=\left\{\mathrm{X}_{1}\right\}, \mathrm{C}_{2}=\left\{\mathrm{X}_{2}\right\}, \mathrm{C}_{3}=\left\{\mathrm{X}_{3}\right\}$,

- two-element combinations: $\mathrm{C}_{4}=\left\{\mathrm{X}_{1}, \mathrm{X}_{2}\right\}, \mathrm{C}_{5}=\left\{\mathrm{X}_{1}, \mathrm{X}_{3}\right\}$, $\mathrm{C}_{6}=\left\{\mathrm{X}_{2}, \mathrm{X}_{3}\right\}$

- three-element combinations: $\mathrm{C}_{7}=\left\{\mathrm{X}_{1}, \mathrm{X}_{2}, \mathrm{X}_{3}\right\}$.

For each above defined combination, the individual information capacity index $h_{m x_{k}}$ is calculated for variable $X_{k}$ in $\mathrm{m}$-th combination of variables:

$$
h_{m x_{k}}=\frac{r_{y x_{k}}^{2}}{1+\sum_{\substack{k, s \in K_{m} \\ k \neq s}}\left|r_{x_{k} x_{s}}\right|}
$$

where:

$r_{y x_{k}}$ - correlation coefficient between dependent variable $Y$ and explanatory variable $X_{k}$ (correlation coefficient matrix $\mathbf{R}_{\mathbf{0}}$ ), $r_{x k x}$ - correlation coefficient between explanatory variables (correlation coefficient matrix R),

$m$ - number of combination,

$k$ - number of explanatory variable $X_{k}$ for which the individual information capacity index $h_{m x_{k}}$ is calculated.

The next step in the Hellwig analysis is calculating the integral information capacity index $H_{m}$ for each combination

$$
H_{m}=\sum_{k \in K} h_{m x_{k}}
$$

The highest value of this index is the criterion for selecting relevant combination of explanatory variables. Indeed, taking into account the goal of analysis, which was sensitivity identification of diagnostic parameters, i.e. concentrations of individual exhaust gas components, to changes of the structure parameter, which was the fuel injection timing, particular attention was focused on those combinations of input parameters which included the structure parameter, i.e. combinations $\mathrm{C}_{3}, \mathrm{C}_{5}, \mathrm{C}_{6}$ and $\mathrm{C}_{7}$.

Due to a large amount of collected empirical material and limited form of the article, the analysis of information capacity index changes was limited to one engine rotation speed, $\mathrm{n}=1100[\mathrm{rpm}]$. The concentrations which were subject to analysis were $\mathrm{HC}, \mathrm{CO}$ and $\mathrm{NO}_{\mathrm{x}}$ concentrations. Moreover, the analysis included changes the excess air number $\lambda$.

The highest values of the index $H_{m}$ were observed for the air excess number $\lambda$, then for the concentration of carbon oxide $\mathrm{CO}$ and unburned hydrocarbons $\mathrm{HC}$. The lowest values of $H_{m}$ were recorded for nitrogen oxides $\mathrm{NO}_{\mathrm{x}}$.

What is noteworthy here is that some regularity can be observed, which is characterised by higher values of index $H_{m}$ recorded for the delayed fuel injection timing $\left(22^{\circ} \mathrm{OWK}\right)$, which undoubtedly has its substantive justification, as the delayed timing affects unfavourably combustion conditions in the engine cylinder. First of all, the excess air number decreases which leads to the creation of incomplete combustion products and, consequently, to the increase of $\mathrm{CO}$ and HC concentrations.

Correct model estimation is also testified by negative correlations for both the excess air number and $\mathrm{NO}_{\mathrm{x}}$ concentration, as local deficit of oxygen leads to the decrease of concentration of this compound.

The highest values of the index $H_{m}$ occur, first of all, for the combination $\mathrm{C}_{5}$, which relates the rotational speed $\left(x_{1}\right)$ and the engine structure parameter, which was the fuel injection timing $\left(x_{3}\right)$, for both delayed and advanced fuel injection. Only slightly lower values of the index $\mathrm{H}_{\mathrm{m}}$ occur for the combination $\mathrm{C}_{7}$ which relates three input quantities of the test plan (Fig. 2-5). 

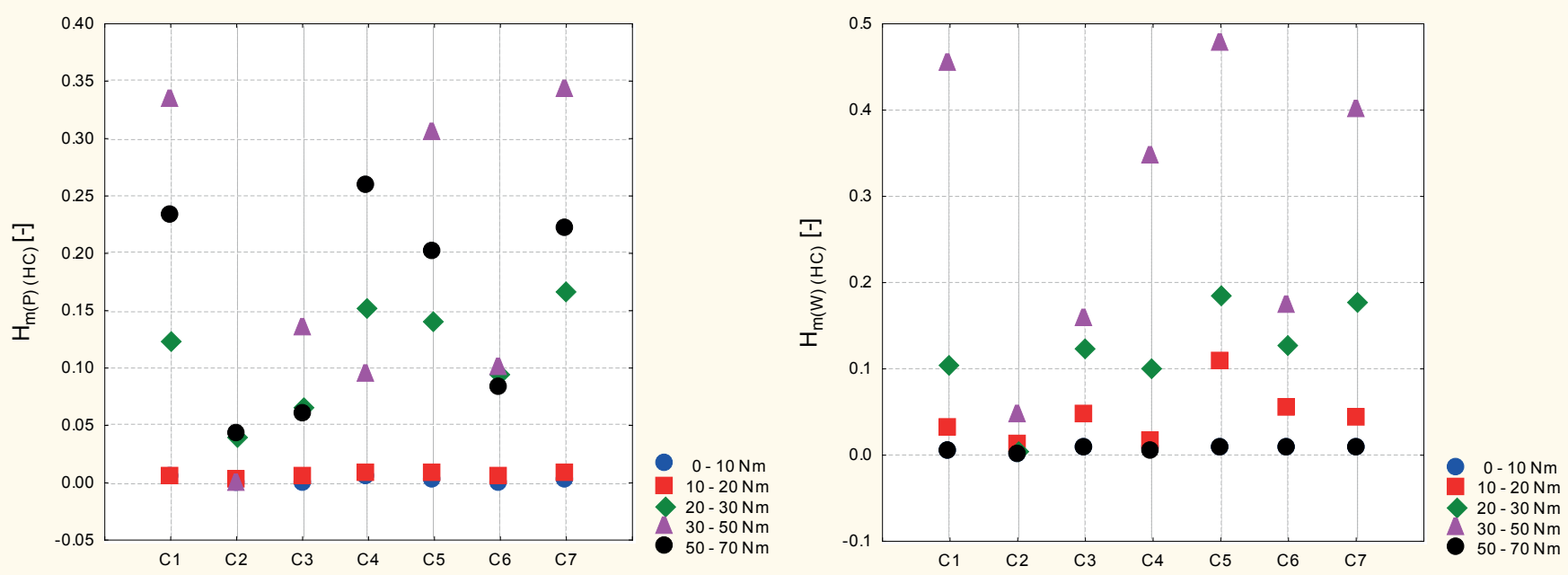

Fig.2. Values of information capacity index Hm for HC and transient state: $n=1100 \mathrm{rpm}$, load change from $T_{t q}=0 \mathrm{Nm}$ to $T_{t q}=70 \mathrm{Nm}$. $P-$ delayed fuel injection timing, $W$-advanced fuel injection timing, C1-C7 - combinations of explanatory variables
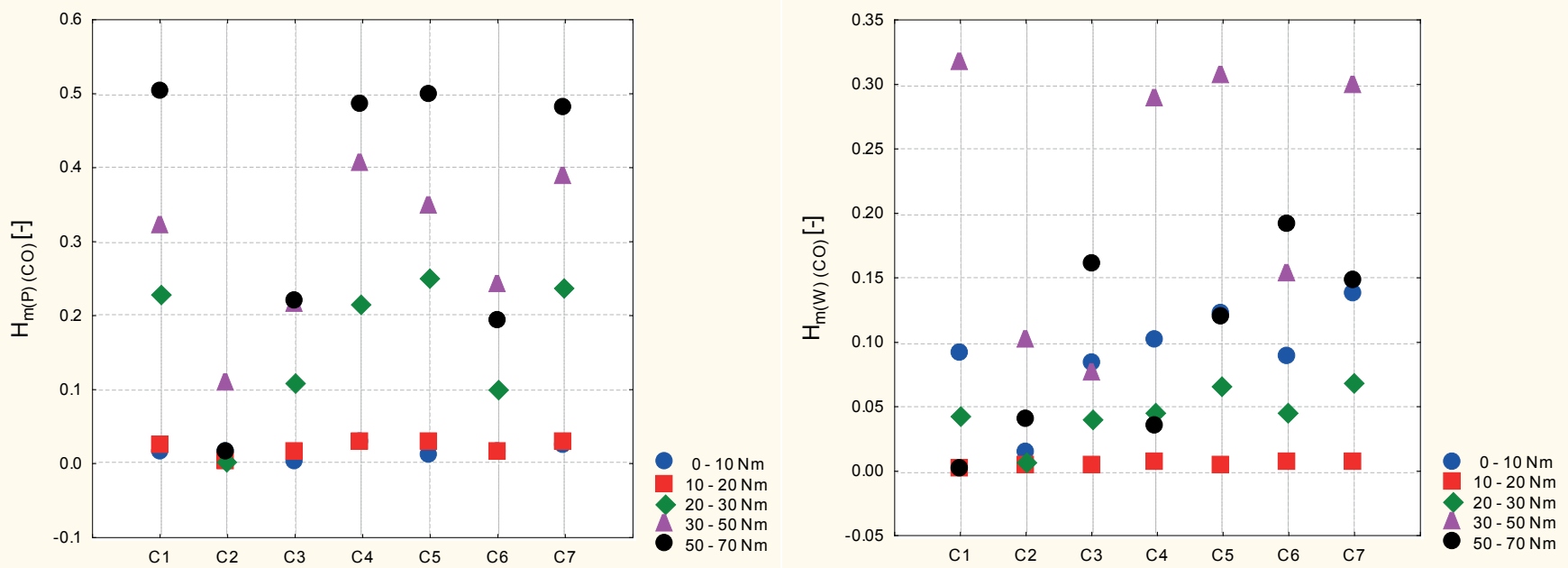

Fig. 3. Values of information capacity index $\mathrm{Hm}$ for CO and transient state: $n=1100 \mathrm{rpm}$, load change from $T_{t q}=0 \mathrm{Nm}$ to $T_{t q}=70 \mathrm{Nm}$ : $P-$ delayed fuel injection timing, $W$ - advanced fuel injection timing, C1 - C7 - combinations of explanatory variables
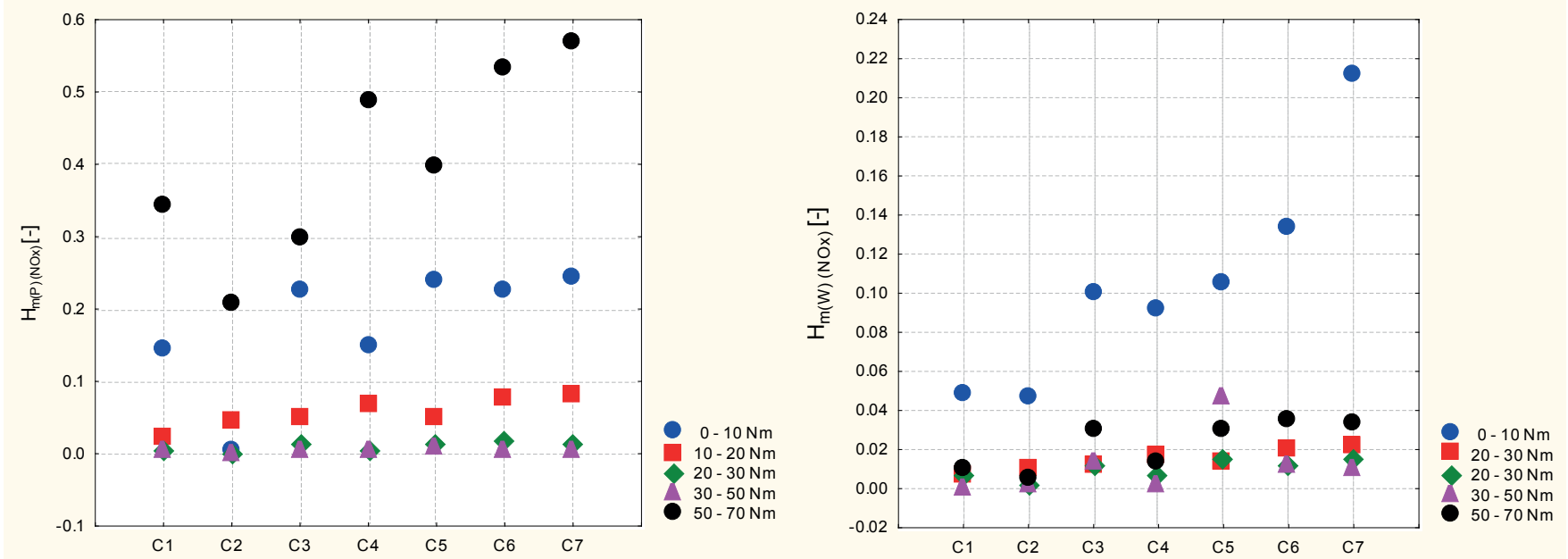

Fig.4. Values of information capacity index $\mathrm{Hm}$ for $\mathrm{NO}_{x}$ and transient state: $n=1100 \mathrm{rpm}$, load change from $\mathrm{T}_{\text {tq }}=0 \mathrm{Nm}$ to $\mathrm{T}_{\mathrm{tq}}=70 \mathrm{Nm}: \mathrm{P}-\mathrm{delayed}$ fuel injection timing, $W-$ advanced fuel injection timing, C1 - C7 - combinations of explanatory variables 

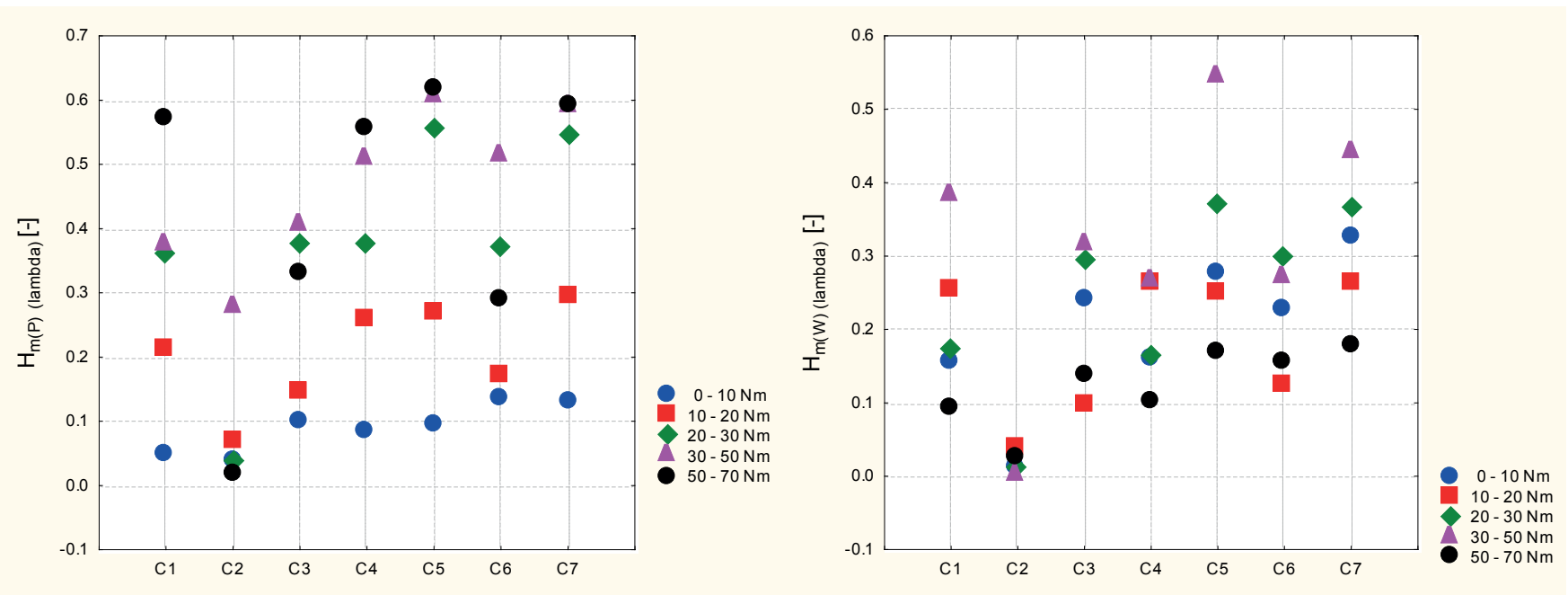

Fig.5. Values of information capacity index $\mathrm{Hm}$ for $\lambda$ and transient state: $n=1100 \mathrm{rpm}$, load change from $T_{\text {tq }}=0 \mathrm{Nm}$ to $T_{\text {tq }}=70 \mathrm{Nm}$ : $P-$ delayed fuel injection timing, $W$ - advanced fuel injection timing, $C 1-C 7-$ combinations of explanatory variables

The analysis of the integral information capacity index $H_{m}$ provides not only the possibility for correct model estimation (for which, in fact, it is intended). Thanks to this analysis, from an extremely large dataset we can, along with specifying important variables, define conditions in which their effect on the examined object is the highest. On the other hand, the $H_{m}$ values are very close to each other which makes it difficult to assess which arrangement of the test plan brings maximal information value, the more so that these values refer to one parameter only, or one combination of those parameters.

In the above situation, what seems to be of some help is the use of a ranking of parameters, as the ranking taking into account multi-criterial assessments (including all parameters and their combinations) is a basic condition for making correct diagnostic decisions.

\section{RANKING CREATION}

Due to a large amount of the recorded research material and the need for objective indication of a most favourable, in sensitivity terms, diagnostic parameter, a ranking was created based on the zero unitarization method. Earlier, each explanatory variable of the test plan was analysed using the information capacity index method (the Hellwig method), therefore at the preliminary stage of ranking creation it was the Hellwig index value which was assumed a diagnostic variable for each explanatory variable. These values for individual test plan arrangements and combinations of input parameters: $\mathrm{HC}, \mathrm{CO}, \mathrm{NO}_{x}$ and $\lambda$, are shown in Fig. 2-5.

The first step of ranking creation was dividing the set of diagnostic variables into three subsets: $S, D$ and $N$, i.e.:

where:

$$
\mathrm{X}=\mathrm{S} \cup \mathrm{D} \cup \mathrm{N}
$$

$S$ - subset of diagnostic variables called stimulators,

$D$ - subset of diagnostic variables called destimulators,

$N$ - subset of diagnostic variables called nominants.
The stimulants were transformed to the normalised form using the relation:

$$
z_{i j}=\frac{x_{i j}-\min _{i} x_{i j}}{\max _{i} x_{i j}-\min _{i} x_{i j}}, \quad\left(\begin{array}{l}
i=1,2, \ldots, r \\
j=1,2, \ldots, s
\end{array}\right), X_{i} \in S
$$

while for the destimulants the normalisation relation had the form:

$$
z_{i j}=\frac{\max _{i} x_{i j}-x_{i j}}{\max _{i} x_{i j}-\min _{i} x_{i j}}, \quad\left(\begin{array}{l}
i=1,2, \ldots, r \\
j=1,2, \ldots, s
\end{array}\right), \quad x_{i}
$$

Combinations $C_{1}, C_{3}, C_{4}, C_{5}$ and $C_{7}$ of the dependent variables were assumed the stimulants, i.e. diagnostic variables the increase of which is to be associated with the increase of the complex phenomenon and the decrease with the decrease. Simultaneously, combinations $C_{2}$ and $C_{6}$ were assumed the destimulants, i.e. diagnostic variables the increase of which is to be associated with the decrease of the complex phenomenon and the decrease - with the increase.

The next step was normalisation of diagnostic indicators. This step is very important, as it provides opportunities for cumulative multi-criterial assessment of the analysed object. The cumulative assessment is obtained via aggregation, i.e. determining the aggregate (synthetic) variable $Q_{i}$.

$$
\mathrm{Q}_{\mathrm{i}}=\frac{1}{\mathrm{~s}} \sum_{\mathrm{j}=1}^{\mathrm{s}} \mathrm{z}_{\mathrm{ij}} \quad(\mathrm{i}=1,2, \ldots, \mathrm{r})
$$

The information on individual values of variable $Q$ makes it possible to create a ranking with respect to non-increasing $Q_{i}$. Indeed, the position in the ranking will depend on the value of the synthetic variable $Q_{i}$, the set of which is collated in Tables 1-4. 
Tab. 1. Values of normalised diagnostic variables and synthetic variable for $H C$

\begin{tabular}{|c|c|c|c|c|c|c|c|c|}
\hline Plan arrangement & $z_{i 1}$ & $\mathrm{z}_{\mathrm{i} 2}$ & $\mathrm{Z}_{\mathrm{i} 3}$ & $\mathrm{Z}_{\mathrm{i} 4}$ & $\mathrm{z}_{\mathrm{i} 5}$ & $\mathrm{Z}_{\mathrm{i} 6}$ & $Z_{i 7}$ & $\mathrm{Q}_{\mathrm{i}}$ \\
\hline 1 & 2 & 3 & 4 & 5 & 6 & 7 & 8 & 9 \\
\hline $1100 \mathrm{P}(50-70)$ & 0,5071 & 0,1178 & 0,3531 & 0,7443 & 0,4104 & 0,5418 & 0,5460 & 3,2205 \\
\hline $1100 \mathrm{P}(30-50)$ & 0,7355 & 1 & 0,8560 & 0,2688 & 0,6361 & 0,4326 & 0,8523 & 4,7813 \\
\hline $1100 \mathrm{P}(20-30)$ & 0,2676 & 0,1692 & 0,4050 & 0,4372 & 0,2849 & 0,4714 & 0,4043 & 2,4396 \\
\hline $1100 \mathrm{P}(10-20)$ & 0,0058 & 0,9571 & 0 & 0,0117 & 0 & 1 & 0 & 1,9746 \\
\hline $1100 \mathrm{~W}(50-70)$ & 0 & 0,9764 & 0,0250 & 0 & 0,0020 & 0,9761 & 0,0013 & 1,9808 \\
\hline $1100 \mathrm{~W}(30-50)$ & 1 & 0 & 1 & 1 & 1 & 0 & 1 & 5,0 \\
\hline $1100 \mathrm{~W}(20-30)$ & 0,2284 & 0,9293 & 0,7909 & 0,2785 & 0,3750 & 0,2822 & 0,4350 & 3,3193 \\
\hline $1100 \mathrm{~W}(10-20)$ & 0,0613 & 0,7302 & 0,2676 & 0,0316 & 0,2154 & 0,7148 & 0,0838 & 2,1047 \\
\hline
\end{tabular}

Tab. 2. Values of normalised diagnostic variables and synthetic variable for CO

\begin{tabular}{|c|c|c|c|c|c|c|c|c|}
\hline Test plan arrangement & $z_{i 1}$ & $\mathrm{z}_{\mathrm{i} 2}$ & $\mathrm{z}_{\mathrm{i} 3}$ & $\mathrm{z}_{\mathrm{i} 4}$ & $z_{i 5}$ & $\mathrm{z}_{\mathrm{i} 6}$ & $z_{i 7}$ & $\mathrm{Q}_{\mathrm{i}}$ \\
\hline 1 & 2 & 3 & 4 & 5 & 6 & 7 & 8 & 9 \\
\hline $1100 \mathrm{P}(50-70)$ & 1 & 0,8520 & 1 & 1 & 1 & 0,1983 & 1 & 6,0503 \\
\hline $1100 \mathrm{P}(30-50)$ & 0,6336 & 0 & 0,9841 & 0,8349 & 0,6928 & 0 & 0,3826 & 3,5280 \\
\hline $1100 \mathrm{P}(20-30)$ & 0,4485 & 1 & 0,4974 & 0,4346 & 0,4992 & 0,6036 & 0,4887 & 3,9720 \\
\hline $1100 \mathrm{P}(10-20)$ & 0,0498 & 0,9880 & 0,0515 & 0,0458 & 0,0515 & 0,9693 & 0,0497 & 2,2056 \\
\hline $1100 \mathrm{~W}(30-50)$ & 0,6280 & 0,0625 & 0,3388 & 0,5913 & 0,6139 & 0,3797 & 0,6186 & 3,2328 \\
\hline $1100 \mathrm{~W}(20-30)$ & 0,0820 & 0,9558 & 0,1736 & 0,0791 & 0,1253 & 0,8331 & 0,1309 & 2,3798 \\
\hline $1100 \mathrm{~W}(10-20)$ & 0,0023 & 0,9687 & 0 & 0 & 0 & 0 & 0 & 0,9710 \\
\hline
\end{tabular}

Tab. 3. Values of normalised diagnostic variables and synthetic variable for $\mathrm{NO}_{x}$

\begin{tabular}{|c|c|c|c|c|c|c|c|c|}
\hline Test plan arrangement & $\mathrm{z}_{\mathrm{i} 1}$ & $\mathrm{z}_{\mathrm{i} 2}$ & $\mathrm{z}_{\mathrm{i} 3}$ & $\mathrm{z}_{\mathrm{i} 4}$ & $\mathrm{z}_{\mathrm{i} 5}$ & $z_{i 6}$ & $\mathrm{z}_{\mathrm{i} 7}$ & $\mathrm{Q}_{\mathrm{i}}$ \\
\hline 1 & 2 & 3 & 4 & 5 & 6 & 7 & 8 & 9 \\
\hline $1100 \mathrm{P}(50-70)$ & 1 & 0 & 1 & 1 & 1 & 0 & 1 & 5,0000 \\
\hline $1100 \mathrm{P}(30-50)$ & 0,0123 & 0,9995 & 0 & 0,0065 & 0 & 1 & 0 & 2,0183 \\
\hline $1100 \mathrm{P}(20-30)$ & 0,0146 & 1 & 0,0266 & 0,0090 & 0,0225 & 0,9754 & 0,0134 & 2,0615 \\
\hline $1100 \mathrm{P}(10-20)$ & 0,0607 & 0,2218 & 0,1419 & 0,1333 & 0,1258 & 0,8656 & 0,1349 & 1,6840 \\
\hline $1100 \mathrm{~W}(50-70)$ & 0,0293 & 0,9788 & 0,0844 & 0,0236 & 0,0681 & 0,9431 & 0,0466 & 2,1739 \\
\hline $1100 \mathrm{~W}(30-50)$ & 0 & 0,9937 & 0,0242 & 0 & 0,1185 & 0,9868 & 0,0067 & 2,1299 \\
\hline $1100 \mathrm{~W}(20-30)$ & 0,0184 & 0,9951 & 0,0181 & 0,0114 & 0,0219 & 0,9859 & 0,0147 & 1,0339 \\
\hline $1100 \mathrm{~W}(10-20)$ & 0,0191 & 0,9499 & 0,0194 & 0,0297 & 0,0190 & 0,9699 & 0,2819 & 2,2889 \\
\hline
\end{tabular}

Tab. 4. Values of normalised diagnostic variables and synthetic variable for $\lambda$

\begin{tabular}{|c|c|c|c|c|c|c|c|c|}
\hline Test plan arrangement & $z_{i 1}$ & $\mathrm{z}_{\mathrm{i} 2}$ & $\mathrm{z}_{\mathrm{i} 3}$ & $\mathrm{z}_{\mathrm{i} 4}$ & $\mathrm{z}_{\mathrm{i5}}$ & $\mathrm{z}_{\mathrm{i} 6}$ & $z_{i 7}$ & $\mathrm{Q}_{\mathrm{i}}$ \\
\hline 1 & 2 & 3 & 4 & 5 & 6 & 7 & 8 & 9 \\
\hline $1100 \mathrm{P}(50-70)$ & 1 & 0,2631 & 0,7524 & 1 & 1 & 0,5723 & 1 & 5,5878 \\
\hline $1100 \mathrm{P}(30-50)$ & 0,5914 & 0 & 1 & 0,9000 & 0,9731 & 0 & 0,9922 & 4,4567 \\
\hline $1100 \mathrm{P}(20-30)$ & 0,5594 & 0,8784 & 0,8980 & 0,6013 & 0,8556 & 0,3661 & 0,8864 & 5,0452 \\
\hline $1100 \mathrm{P}(10-20)$ & 0,3544 & 0,9992 & 0,0061 & 0,2976 & 0,0696 & 0,7786 & 0,1372 & 2,6427 \\
\hline $1100 \mathrm{~W}(30-50)$ & 0,6119 & 1 & 0,7024 & 0,3682 & 0,8409 & 0,6193 & 0,6347 & 4,7774 \\
\hline $1100 \mathrm{~W}(20-30)$ & 0,1672 & 0,9736 & 0,6345 & 0,1446 & 0,4508 & 0,5486 & 0,4542 & 3,3735 \\
\hline $1100 \mathrm{~W}(10-20)$ & 0,3356 & 0,8755 & 0 & 0,3539 & 0,1795 & 1 & 0,2037 & 2,9482 \\
\hline
\end{tabular}


When analysing the tables with normalised diagnostic variables we can notice that their highest values refer to arrangements executed at the delayed fuel injection $\left(22^{\circ} \mathrm{OWK}\right)$, for both $\mathrm{CO}$ and $\mathrm{NO}_{\mathrm{x}}$ concentrations, and the excess air number $\lambda$. A characteristic test plan arrangement is the arrangement $1100 \mathrm{P}(50-70)$, representing the transient state executed at the rotational speed of $1100 \mathrm{rpm}$, when the load changes from 50 to $70 \mathrm{Nm}$, and for the delayed fuel injection angle, equal to $22{ }^{\circ} \mathrm{OWK}$ (Table $\left.1-4\right)$. The next arrangements in the information capacity ranking which are characteristic for high values of normalised diagnostic variables are those executed for intermediate loads, i.e. in the first place for the load change from 20 to $30 \mathrm{Nm}$ and then, for the change from 30 to $50 \mathrm{Nm}$. This mainly refers to changes of $\mathrm{CO}$ concentration and the excess air number $\lambda$. As for $\mathrm{NO}_{\mathrm{x}}$ concentration (Table 4), the next arrangements in the ranking are those executed for similar load changes but for the advanced fuel injection angle, $\left(30^{\circ} \mathrm{OWK}\right)$. This has its substantive justification resulting from the physics of creation of individual toxic compounds in the cylinder. For instance, the dominant for the creation of nitrogen oxides is, first of all, high combustion pressure, at high excess air number, and the accompanying high combustion temperature.

Like for $\mathrm{NO}_{\mathrm{x}}$ concentrations (apart from arrangement 1), for hydrocarbon concentrations, (Table 1) we can notice that the highest values refer to the test plan arrangement $1100 \mathrm{~W}(30-50)$, i.e. to the transient state executed at rotational speed of $1100 \mathrm{rpm}$, when the load changes from 30 to $50 \mathrm{Nm}$ and for the advanced fuel injection angle, equal to $30^{\circ} \mathrm{OWK}$. This may testify to the fact that this arrangement carries the greatest information value. The next arrangement in the information capacity ranking with respect to changes of structural parameters of the fuel supply system is the arrangement $1100 \mathrm{P}(30-50)$, with the ranking values only slightly lower than the top values. It is noteworthy that in both cases these arrangements do not represent the highest moment load. In this context a conclusion can be made that when arranging diagnostic tests, an important role in measurements can be played by intermediate load variants.

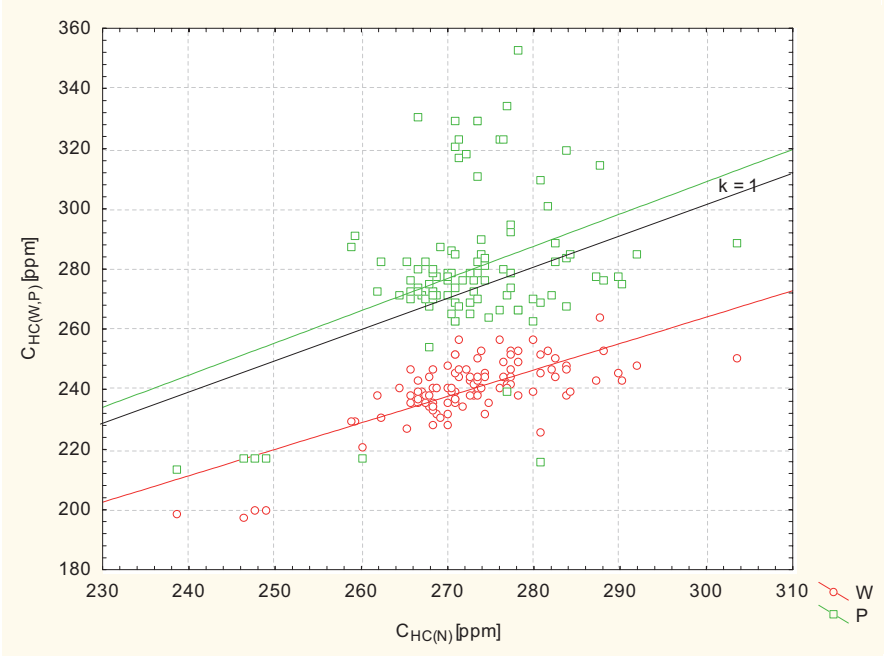

The above presented approach to ranking creation, which consists in considering all variables only as stimulants and destimulants, can be considered sufficient in the case when those variables are independent from each other, or their values are significantly different. When creating the ranking taking into account interactions between individual elements (which is the case here for the exhaust gas components) and changes in the structure parameter (fuel injection timing), this parameter is to be included in the subset of nominants, i.e. variables which have the most favourable value in the context of the analysed aspect of study. This way the fuel injection timing as the nominant will have a specified nominal value for the state of object serviceability. This nominal value will correspond to nominal concentrations of the earlier analysed $\mathrm{CO}, \mathrm{HC}$ and $\mathrm{NO}_{\mathrm{x}}$ compounds, and the excess air number $\lambda$.

A classical version of the zero unitarization method considers two approaches to $\mathrm{HC}$ and CO normalisation. The former approach refers to the case when only one nominal value $c_{0 j}$ exists, and in that case the normalisation is performed using formula (8). In the latter case, when the nominal values compose an interval $\left[c_{1 j}, c_{2 j}\right]$, the normalisation formula (9) is applied.

$$
\begin{aligned}
& z_{i j}=\left\{\begin{array}{c}
\frac{x_{i j}-\min _{i} x_{i j}}{c_{0 j}-\min _{i} x_{i j}}, \quad g d y x_{i j}<c_{0 j}, \\
1, \quad g d y x_{i j}=c_{0 j}, \quad x_{i} \in N, \\
\frac{x_{i j}-\max _{i} x_{i j}}{c_{0 j}-\max _{i} x_{i j}}, \quad g d y x_{i j}>c_{0 j}
\end{array}\right.
\end{aligned}
$$

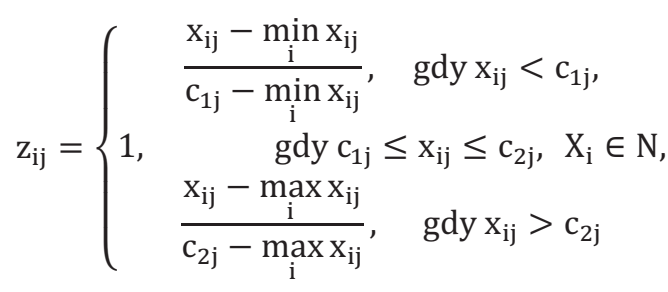

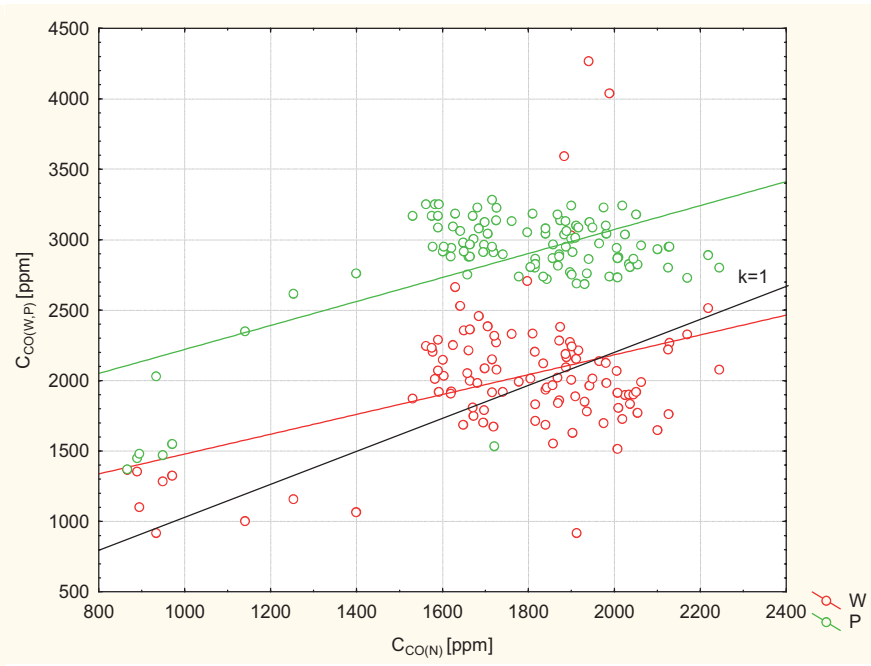

Fig. 6. Values of $\mathrm{HC}$ and $\mathrm{CO}$ concentration for transient state at $n=1100 \mathrm{rpm}$ and load change from $T_{t q}=0 \mathrm{Nm}$ to $T_{t q}=70 \mathrm{Nm}: C_{H C(N, W, P)}-H C$ concentration, $C_{C O(N, W, P)}-C O$ concentration for nominal $(N)$, advanced $(W)$, and delayed $(P)$ fuel injection timing 
The above described way of data analysis, in which the information capacity index values are analysed for individual test plan arrangements, will base on an interval of nominal values, which suggests that the formula (9) is to be used.

However, in the analysed case, due to the goal of the performed analysis, the highest information value will be attributed to test plan arrangements with values significantly differing from that determined by the nominal value interval. Graphical illustration of this problem is the dispersion diagram in Fig. 6, which shows the linear correlation function for concentration of unburned hydrocarbons $\mathrm{HC}$ and carbon oxide $\mathrm{CO}$, and its position with respect to nominal values (black lines). That is why the normalisation formula (10) was applied in the present analysis.

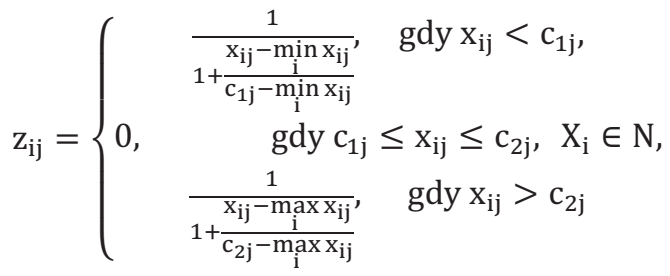

The values obtained from normalisation of nominants of individual variables were aggregated with corresponding values of stimulants and destimulants (Tab. 1-4). As a result, synthetic variables were obtained which can be considered multi-criterial assessments of the influence of fuel injection timing.

As already mentioned, the position in the ranking will depend on the value of the synthetic variable $Q_{i}$. To organize objects (in the analysed case: normalised diagnostic indicators) with respect to non-increasing $Q_{i}$ values, the entire set of objects can be divided into three parts, being the subgroups of best, average, and worst objects. For this purpose, the constant $U$ can be used in the form:

$$
U=\frac{\max _{i} Q_{i}-\min _{i} Q_{i}}{3}
$$

This way leads to the creation of the subgroup of best objects for $Q_{i} \in\left(\max _{i} Q_{i}-U, \max _{i} Q_{i}\right]$, the subgroup of average objects for $Q_{i} \in\left(\max _{i} Q_{i}-2 U, \max _{i} Q_{i}\right]$ and the subgroup of worst objects for $Q_{i} \in\left(\min _{i} Q_{i}, \max _{i} Q_{i}-2 U\right]$.

Tab. 5. Values of synthetic variables for $\mathrm{HC}, \mathrm{CO}, \mathrm{NO}$, and $\lambda$
The normalisation of synthetic variables performed in the above way is presented in Table 5, in which, for better display of their values, the subgroups of best and average objects are marked green and yellow, respectively.

When analysing the synthetic variable values collated in Table 5, it is noteworthy that compared to values which did not take into account nominants, (Tables 1-4) the test plan arrangements which reveal the highest information value remain basically unchanged, although taking into account the nominal values has led to the increase of differences between the variable values. This is an obvious advantage which makes the ranking easier to analyse. The highest values were observed for the delayed fuel injection angle, for $\mathrm{NO}$ and $\mathrm{CO}$ concentrations in the arrangement executed at load change from $50 \mathrm{Nm}$ to $70 \mathrm{Nm}$. A slightly lower value of the synthetic variable was observed for the excess ait number in the same test plan arrangement. It is noteworthy that this is the parameter for which the largest population of arrangements with highest information values exist. This undoubtedly has its substantive justification, as even small disturbances of the combustion process result in changes of the excess air number $[1,2,4]$. Comparing synthetic variable values for $\mathrm{NO}_{\mathrm{x}}$ concentration is also very interesting, as the majority of measuring arrangements of the test plan have average information value (most frequently in its upper limit). This can be explained by strong correlation of $\mathrm{NO}_{\mathrm{x}}$ concentration with the combustion temperature and the excess air number. Concentration changes are rather small, but always occur when changing one of the abovenamed factors. This suggests a conclusion that the analysis of the relationship between $\mathrm{NO}_{x}$ concentration and the excess air number should be given more attention.

\section{SUMMARY}

The values of $H_{m}$, coefficient, which are close to each other, do not provide an answer to the question which test plan arrangement brings the maximal information value due to changes in the structure of the object of analysis, the more so that they refer to only one parameter or one combination of parameters. On the other hand, the ranking taking into account multi-criterial assessments (including all parameters and their combinations) is a basic condition for making correct diagnostic decisions. More complicated rankings can

\begin{tabular}{|c|c|c|c|c|}
\hline Test plan arrangement & $\mathrm{Q}_{\mathrm{i}(\mathrm{HC})}$ & $\mathrm{Q}_{\mathrm{i}(\mathrm{CO})}$ & $\mathrm{Q}_{\mathrm{i}(\mathrm{NOx})}$ & $\mathrm{Q}_{\mathrm{i}(\lambda)}$ \\
\hline 1 & 2 & 3 & 4 & 5 \\
\hline $1100 \mathrm{P}(50-70)$ & 3,2205 & 11,5616 & 12,000 & 10,1481 \\
\hline $1100 \mathrm{P}(30-50)$ & 6,3675 & 7,7194 & 7,6813 & 10,6292 \\
\hline $1100 \mathrm{P}(20-30)$ & 2,4396 & 3,9720 & 7,9542 & 8,9860 \\
\hline $1100 \mathrm{P}(10-20)$ & 1,9746 & 3,8689 & 2,3474 & 2,6427 \\
\hline $1100 \mathrm{~W}(50-70)$ & 3,9808 & 4,2771 & 6,7428 & 2,9723 \\
\hline $1100 \mathrm{~W}(30-50)$ & 11,0000 & 4,6686 & 6,7000 & 8,2111 \\
\hline $1100 \mathrm{~W}(20-30)$ & 3,3193 & 2,3798 & 6,6309 & 5,8062 \\
\hline $1100 \mathrm{~W}(10-20)$ & 2,1047 & 4,9347 & 7,2735 & 3,4513 \\
\hline
\end{tabular}


be created which take into account, for instance, compilation of explanatory and dependent variables, for the ranking to cover simultaneously all toxic compounds recorded during the experiment along will other parameters essential for the correctness of the combustion process.

Referring directly to the results of the presented ranking, some regularity in their distribution is worth noticing. Namely, except the absolutely highest value, in all remaining cases higher values of synthetic variable $Q_{i}$ were observed for the delayed fuel injection angle $\left(22^{\circ} \mathrm{OWK}\right)$. This undoubtedly has its substantive justification, as the delayed fuel injection affects unfavourably combustion conditions in the engine cylinder. First of all, the excess air number decreases which leads to the creation of incomplete combustion products and, consequently, to the increase of $\mathrm{CO}$ and $\mathrm{HC}$ concentrations, which were the main object of this analysis.

\section{BIBLIOGRAPHY}

1. Markowski J.: Emission of harmful exhaust gas compounds from aircraft piston engines (in Polish). Poznan University of Technology, Thesis no. 517, ISSN: 0551-6528, Poznan 2013.

2. Pielecha J.: Identifying parameters of particulates from internal combustion engines (in Polish). Poznan University of Technology, Thesis no. 467, ISSN: 0551-6528, Poznan 2012.

3. Rudnicki J., Zadrag R.: Problems of modelling toxic compounds emitted by a marine internal combustion engine in unsteady states. POLISH MARITIME RESEARCH, Vol. 21, ISSN: 1233-2585, pp. 57-65, Gdansk 2014.

4. Zadrąg R.: Criteria for the selection of the diagnostic parameter for diagnosis of marine diesel engine, LOGISTYKA No. 4/2010, ISSN 1231-5478, Poznan 2010.

5. Zadrąg R., Zellma M.: Modelling of toxic compounds emission in marine diesel engine during transient states at variable pressure of fuel injection. JOURNAL OF POLISH CIMAC, Vol.8, No 1, ISSN 1231-3998, Gdansk 2014.

6. Zadrąg R., Kniaziewicz T.: The identification of toxic compound emission sensitivity as a diagnostic parameter during dynamic processes of the marine engine. JOURNAL OF POLISH CIMEEAC, Vol.10, No 1, ISSN 1231-3998, pp. 161-170, Gdansk 2015.

7. Zadrąg R., Kniaziewicz T.: Identification of diagnostic parameter sensitivity during dynamic processes of a marine engine. The $6^{\text {th }}$ INTERNATIONAL CONGRESS ON COMBUSTION ENGINES, PTNSS-2015-3507, Olsztyn 2015.

\section{CONTACT WITH THE AUTHORS}

\author{
Ryszard Zadrąg \\ e-mail:r.zadrag@amw.gdynia.pl \\ Polish Naval Academy \\ 69 Śmidowicza St. \\ 81-127 Gdynia
}

